\title{
Changes in Dynamical Behavior of the Retinoid X Receptor DNA-Binding Domain upon Binding to a 14 Base-Pair DNA Half Site ${ }^{\dagger}$
}

\author{
Paul J. A. van Tilborg, Michael Czisch, Frans A. A. Mulder, Gert E. Folkers, Alexandre M. J. J. Bonvin, \\ Margie Nair, ${ }^{\S}$ Rolf Boelens, and Robert Kaptein* \\ Bijvoet Center for Biomolecular Research, NMR Spectroscopy Department, Utrecht University, \\ Padualaan 8, NL-3584 CH Utrecht, The Netherlands
}

Received July 6, 1999; Revised Manuscript Received March 29, 2000

\begin{abstract}
The retinoid X receptor (RXR) is a prominent member of the nuclear receptor family of ligandinducible transcription factors. Many proteins of this family exert their function as heterodimers with RXR as a common upstream partner. Studies of the DNA-binding domains of several nuclear receptors reveal differences in structure and dynamics, both between the different proteins and between the freeand DNA-bound receptor DBDs. We investigated the differences in dynamics between RXR free in solution and in complex with a 14 base-pair oligonucleotide, using ${ }^{1} \mathrm{H}$ and ${ }^{15} \mathrm{~N}$ relaxation studies. Nano- to picosecond dynamics were probed on ${ }^{15} \mathrm{~N}$, employing Lipari-Szabo analysis with an axially symmetric tumbling model to estimate the exchange contributions to the transverse relaxation rates. Furthermore, milli- to microsecond dynamics were estimated qualitatively for ${ }^{1} \mathrm{H}$ and ${ }^{15} \mathrm{~N}$, using CPMG-HSQC and CPMG- $\mathrm{T}_{2}$ measurements with differential pulse spacing. RXR shows hardly any nano- to picosecond time-scale internal motion. Upon DNA binding, the order parameters show a tiny increase. Dynamics in the milli- to microsecond time scale is more prevalent. It is localized in the first and second zinc fingers of the free RXR. Upon DNA-binding, exchange associated with specific/aspecific DNA-binding of RXR is observed throughout the sequence, whereas conformational flexibility of the D-box and the second zinc finger of RXR is greatly reduced. Since this DNA-binding induced folding transition occurs remote from the DNA in a region which is involved in protein-protein interactions, it may very well be related to the cooperativity of dimeric DNA binding.
\end{abstract}

The retinoid X receptor RXR is a member of the family of nuclear receptors. These ligand-inducible transcription factors regulate gene transcription by binding specific DNA sequences, the so-called hormone response elements (HREs). ${ }^{1}$ The HREs consist of two copies of a consensus hexamer motif (AGGTCA), organized in various ways $(1)$. The exact organization of these DNA sequences (direct repeats or palindromes, and the number of spacing base pairs between them) determine to a large extent the protein specificity $(2,3)$.

The nuclear receptors are organized into three functional domains, the central of which is the DNA-binding domain (DBD). The three-dimensional structure of many nuclear receptor DBDs have been determined (4-17), giving a

† This research has been financially supported by the council for chemical sciences of The Netherlands organization for scientific research $(\mathrm{CW} / \mathrm{NWO})$.

* To whom correspondence should be addressed. Phone: 3130 2532652. Fax: 3130 2537623. E-mail: kaptein@nmr.chem.uu.nl.

Current address: Department of Medical Genetics \& Microbiology, University of Toronto, 1 King's College Circle, M5S 1A8 Toronto, Canada.

$\S$ Current address: Biomolecular Research Institute, NMR Laboratory, 343 Royal Parade, Parkville 3052, Melbourne, Australia.

1 Abbreviations: DBD, DNA-binding domain; DR, direct repeat; DTT, dithiothreitol; EDTA, ethylenediaminetetraacetic acid; ER, oestrogen receptor; GR, glucocorticoid receptor; GST, glutathione- $S$-transferase; HRE, hormone response element; RAR, retinoic acid receptor; $\mathrm{RXR}$, retinoid X receptor; TR, thyroid hormone receptor. wealth of structural information. Considering the high sequence homology between the receptors, it is not surprising that these structures are very much alike. All nuclear receptors exhibit a similar fold, consisting of two copies of a zinc finger subdomain, in which a zinc ion is coordinated by four cysteines, immediately followed by a helix. The two helices are oriented almost perpendicularly.

However, some interesting differences are observed between the family members. For the oestrogen receptor ER $(5,11)$ and $\operatorname{RXR}(6,10)$, as well as for a longer construct of the glucocorticoid receptor GR $(4,8)$, a largely distorted second zinc finger was observed, whereas shorter constructs of $\operatorname{GR}(7,17)$ reveal a distorted helix. In the retinoic acid receptor RAR (9), both zinc fingers are slightly disordered. Furthermore, the solution structure of RXR free in solution (10) distinguishes itself from its relatives by the presence of a $\alpha$-helix in the C-terminal extension of the DBD, which is not observed in any other receptor.

Besides the structural differences, also differences in dynamics have been observed. Initial NMR studies of the dynamics of GR, ER, and RXR (18-20) only showed minor nano- to picosecond time-scale mobility. In GR and RXR, these were mainly located in the first and second zinc finger, respectively. Recently, extensive milli- to microsecond motions were detected in $\operatorname{RAR}$ and $\operatorname{RXR}(21,22)$ and also in ER and GR (23). The differences in the position and extent 
of conformational averaging in each of the receptors suggests biological relevance of the motion in molecular recognition upon DNA binding.

Structural differences were also observed between the solution structures of the free protein and the crystal structures of the proteins in complex with DNA (13-15). The tip of the second zinc finger, which is disordered in the free RXR and ER, folds to a distorted helix if the protein is complexed to DNA. Furthermore, in all nuclear receptors the conformation of the D-box alters upon binding to DNA. In the crystal structure of ER, the tip of the second zinc finger in the two different dimers of the unit cell exhibit different conformations (13). One dimer contains a distorted helix, similar to the glucocorticoid receptor (GR) (12). In the other, the tip is partially unfolded due to crystal packing, which supports the idea that the structure is at best marginally stable in solution (13). Independent evidence for a local folding event upon DNA binding of GR is provided by thermodynamic studies, which showed large negative changes in the heat capacity upon complex formation. These heat capacity changes were associated with a local folding of about 17 residues/GR molecule, consistent with the number of residues in the second zinc finger (24).

It was noted early on that for high-affinity DNA binding the $\mathrm{C}$-domain alone does not suffice. Deletion mutagenesis experiments indicated the need for the first $12-15$ residues of the D-domain for ER, GR, and RAR, and even 24 residues in the case of TR, to achieve optimal DNA binding (25). As was mentioned before, RXR is the only receptor to contain an $\alpha$-helix in the T-box, when free in solution $(6,10)$. However, this helix was reported to unfold upon complex formation $(26,15)$. In the TR crystal structure, a helix was observed in a region $\mathrm{C}$-terminal to the $\mathrm{T}$-box, called the A-box (15).

Here, we present ${ }^{1} \mathrm{H}$ and ${ }^{15} \mathrm{~N}$ relaxation data, obtained for RXR free in solution and complexed to a 14 base-pair oligonucleotide, containing a RXR half-site. Lipari-Szabo analysis of the ${ }^{15} \mathrm{~N}$ data (taking rotational diffusion anisotropy into account) and qualitative estimates of the ${ }^{1} \mathrm{H}$ and ${ }^{15} \mathrm{~N}$ exchange revealed dynamics associated with the equilibrium between specific and aspecific RXR-DNA complexes. Furthermore, milli- to picosecond time-scale flexibility in the dimerization regions of RXR greatly reduces upon complex formation. These results provide evidence for a folding transition which may be related to the cooperativity of dimeric nuclear receptor DBD binding to DNA.

\section{MATERIALS AND METHODS}

Protein Expression and Purification. The hRXR $\alpha$ (132209), with a C195A substitution, was expressed and purified as described (21). The two zinc ions, initially present in the protein, are substituted by cadmium ions according to the following procedure. Approximately $10 \mathrm{mg}$ of $\mathrm{RXR}$ is dissolved in $2 \mathrm{~mL}$ of buffer A [200 mM KCl, $3 \mathrm{mM}$ DTT, $50 \mathrm{mM}$ imidazole ( $\mathrm{pH} 6.6$ ), approximately $0.1 \mathrm{mM} \mathrm{NaN}_{3}$, $5 \%$ glycerol]. This solution is subsequently washed with 6 $\mathrm{mL}$ of buffer $\mathrm{B}$ [buffer $\mathrm{A}+50 \mathrm{mM} \mathrm{CdCl}_{2}+50 \mathrm{mM}$ EDTA] and $6 \mathrm{~mL}$ of buffer A again. Addition of the EDTA prevents the cadmium from precipitating at these $\mathrm{pH}$ values. Subsequently, the sample is exchanged to NMR conditions. All washing is performed with an Amicon dialysis flow cell.
Exchanging the zinc with cadmium ions, together with the cysteine substitution, drastically improves the long-term stability of the protein.

DNA Purification. Two complementary strands (14 base nucleotides: 5'-GGCAAGTTCACTCG-3') of DNA were purchased from Carl Roth $\mathrm{GmbH} \& \mathrm{Co}$. Each strand was purified using a Q-sepharose ion exchange column, eluting with a linear salt gradient of 0 to $1.5 \mathrm{M} \mathrm{KCl}$, at $\mathrm{pH} 9$. The strands were mixed in a 1:1 ratio based on UV extinction and subsequently desalted with an Amicon dialysis flow cell.

Sample Preparation. The sample of the free protein consisted of approximately $1.5 \mathrm{mM} \operatorname{RXR}\{\mathrm{Cd}\}, 200 \mathrm{mM}$ $\mathrm{NaCl}, 3 \mathrm{mM}$ DTT, and approximately $0.1 \mathrm{mM} \mathrm{NaN}_{3}$ in $95 \% /$ $5 \% \mathrm{H}_{2} \mathrm{O} / \mathrm{D}_{2} \mathrm{O}$, with the $\mathrm{pH}$ adjusted to 6.8. All spectra of the free RXR were recorded at $298 \mathrm{~K}$. The RXR-DNA complex was prepared by adding small aliquots of a protein solution (approximately $2 \mathrm{mM} \mathrm{RXR}\{\mathrm{Cd}\}, 200 \mathrm{mM} \mathrm{NaCl}, 3$ mM DTT, pH 6.9) to a DNA solution (approximately $2 \mathrm{mM}$ DNA, $20 \mathrm{mM} \mathrm{NaCl}, \mathrm{pH}$ 7.0). The titration was followed by NMR until a 1:1 ratio was obtained. The final sample conditions of the protein-DNA complex (approximately 1.5 mM RXR-DNA, 75 mM NaCl, 3 mM DTT) were obtained using an Amicon dialysis flow cell. The resulting complex did not show any significant degradation for several months. The $\mathrm{pH}$ was adjusted to 6.7 , and all spectra were recorded at $304 \mathrm{~K}$.

Resonance Assignments. Assignment of the resonances of ${ }^{15} \mathrm{~N} /{ }^{13} \mathrm{C} \operatorname{RXR}\{\mathrm{Cd}\}$ was accomplished using triple resonance experiments. All spectra were recorded on a Varian Inova $500 \mathrm{MHz}$ spectrometer, equipped with a triple resonance $\mathrm{HCN}$ probe and a shielded $z$-gradient. The $\left({ }^{15} \mathrm{~N},{ }^{1} \mathrm{H}\right) \mathrm{HSQC}$ (27), HNCO, HNCA (28), CBCA(CO)NH $(29,30)$, HBHA(CBCACO)NH (31), HNCACB $(30,32)$, HN(CA)HA (33), and $\mathrm{C}(\mathrm{CO}) \mathrm{NH}(34)$ were all recorded with gradient coherence selection and a sensitivity enhancement scheme (35-37). The $\mathrm{C}(\mathrm{CO}) \mathrm{NH}_{2}$ experiments were recorded by adjusting the $\left({ }^{15} \mathrm{~N},{ }^{1} \mathrm{H}\right)$ reverse INEPT magnetization transfer delay from 5.5 to $2.75 \mathrm{~ms}$. The spectra were processed using the NMRPipe software (38). The data were apodized using sinebell and squared sine-bell window functions shifted by $0.3 \pi$ or $0.4 \pi$. Linear prediction in the ${ }^{15} \mathrm{~N}$ dimension and zerofilling were applied prior to Fourier transformation. Final matrixes of the 3D spectra consisted typically of $256\left({ }^{1} \mathrm{H}\right.$ or $\left.{ }^{13} \mathrm{C}\right), 128\left({ }^{15} \mathrm{~N}\right)$, and $1024\left({ }^{1} \mathrm{H}\right)$ points. The Regine software package (39) was used for data analyses.

The assignment procedure yielded $88 \%$ of all backbone ${ }^{15} \mathrm{~N},{ }^{1} \mathrm{H}^{\mathrm{N}}$, and ${ }^{13} \mathrm{C}^{\beta}$ resonances and 86,92 , and $78 \%$ for the ${ }^{13} \mathrm{C}^{\prime},{ }^{13} \mathrm{C}^{\alpha}$, and ${ }^{1} \mathrm{H}^{\alpha}$ resonances, respectively.

Relaxation Measurements. The relaxation data for the free protein are taken from Mulder et al. (22). Performance of the relaxation measurements and extraction of the relaxation rates for the complex are essentially performed as described by Vis et al. (40) for the longitudinal relaxation rate $\left(R_{1}\right)$ and the ${ }^{15} \mathrm{~N}\left\{{ }^{1} \mathrm{H}\right\}$ heteronuclear NOE, and by Düx et al. (41) for the relaxation rates in the rotating frame $\left(R_{1 \rho}\right)$. Measurements of the protein-DNA complex were performed on a Varian Inova $500 \mathrm{MHz}$ spectrometer, equipped with a $5 \mathrm{~mm}$ triple resonance $(\mathrm{HCN})$ probehead with a shielded $z$-gradient. Typical data sets with $50 \times 768$ complex points in the $t_{1}-t_{2}$ dimensions, with spectral widths of 1271 and $7000 \mathrm{~Hz}$ in $F_{1}$ and $F_{2}$, respectively, were acquired. Relaxation delays of $32,64,128,256,512,880$, and $1200 \mathrm{~ms}$ were used for 
Table 1: Expressions for Spectral Density Functions

\begin{tabular}{|c|c|c|}
\hline model & spectral density function & $\begin{array}{l}\text { optimized } \\
\text { parameters }\end{array}$ \\
\hline 1 & $J(\omega)=2 / 5\left[S^{2} \tau_{\mathrm{m}} /\left(1+\omega^{2} \tau_{\mathrm{m}}{ }^{2}\right)\right]$ & $S^{2}$ \\
\hline $2^{a}$ & $J(\omega)=2 \int_{5}\left[S^{2} \tau_{\mathrm{m}} /\left(1+\omega^{2} \tau_{\mathrm{m}}^{2}\right)+\left(1-S^{2}\right) \tau_{\mathrm{e}}^{\prime} /\left(1+\omega^{2} \tau_{\mathrm{e}}^{\prime 2}\right)\right]$ & $S^{2}, \tau_{\mathrm{e}}$ \\
\hline 3 & $J(\omega)=2 / 5\left[S^{2} \tau_{\mathrm{m}} /\left(1+\omega^{2} \tau_{\mathrm{m}}^{2}\right)\right]$ & $S^{2}, R_{\mathrm{ex}}$ \\
\hline & $1 / T_{2(\mathrm{obs})}=1 / T_{2}+R_{\mathrm{ex}}$ & \\
\hline 4 & $\begin{array}{l}J(\omega)=2 / 5\left[S^{2} \tau_{\mathrm{m}} /\left(1+\omega^{2} \tau_{\mathrm{m}} 2\right)+\left(1-S^{2}\right) \tau_{\mathrm{e}}^{\prime} /\left(1+\omega^{2} \tau_{\mathrm{e}}^{\prime 2}\right)\right] \\
1 / T_{2}(\mathrm{obs})=1 / T_{2}+R_{\mathrm{ex}}\end{array}$ & $S^{2}, \tau_{\mathrm{e}}, R_{\mathrm{ex}}$ \\
\hline $5^{b}$ & $J(\omega)=2 /_{5}\left[S^{2} \tau_{\mathrm{m}} /\left(1+\omega^{2} \tau_{\mathrm{m}}^{2}\right)+S_{\mathrm{f}}^{2}\left(1-S_{\mathrm{s}}^{2}\right) \tau_{\mathrm{s}}^{\prime} /\left(1+\omega^{2} \tau_{\mathrm{s}}^{\prime 2}\right)\right]$ & $S_{\mathrm{f}}^{2}, S_{\mathrm{s}}^{2}, \tau_{\mathrm{e}}$ \\
\hline 6 & $\begin{array}{l}J(\omega)=2 /_{5}\left[S^{2} \tau_{\mathrm{m}} /\left(1+\omega^{2} \tau_{\mathrm{m}}^{2}\right)+S_{\mathrm{f}}^{2}\left(1-S_{\mathrm{s}}^{2}\right) \tau_{\mathrm{s}}^{\prime} /\left(1+\omega^{2} \tau_{\mathrm{s}}^{\prime 2}\right)\right] \\
1 / T_{2(\mathrm{obs})}=1 / T_{2}+R_{\mathrm{ex}}\end{array}$ & $S_{\mathrm{f}}^{2}, S_{\mathrm{s}}^{2}, \tau_{\mathrm{e}}, R_{\mathrm{ex}}$ \\
\hline
\end{tabular}

determining $R_{1}$, collecting 96 scans per FID. Relaxation delays of $8,16,32,48,64,96$, and $128 \mathrm{~ms}$ were used for the $R_{1 \rho}$ series, acquiring 56 scans/FID. For the ${ }^{15} \mathrm{~N}\left\{{ }^{1} \mathrm{H}\right\}$ NOE, 160 scans per increment were recorded.

The presence of chemical exchange on the amide protons was derived from the CPMG-HSQC (42) experiments which were recorded and analyzed as described by Van Tilborg et al. (21). Qualitative exchange rates for ${ }^{15} \mathrm{~N}$ magnetization were determined by a simple modification of an experiment for determination of the $T_{2}$ relaxation time employing a CPMG pulse train (42). Two experiments were recorded with the same effective transverse relaxation delay of $32 \mathrm{~ms}$ and an interpulse delay between succesive ${ }^{15} \mathrm{~N}$ refocusing pulses of $1.2 \mathrm{~ms}$ and $400 \mu \mathrm{s}$, respectively. The intensities which can be derived from these spectra are $I_{\text {fast }}^{\mathrm{N}}$ and $I_{\text {slow }}^{\mathrm{N}}$, respectively. To compensate for the different radio frequency, heating a dummy CPMG sequence with interpulse delays of $400 \mu \mathrm{s}$ and $1.2 \mathrm{~ms}$, respectively, was applied between individual scans; 160 scans were added per increment. The spectral widths were the same as described above.

Strategy for Optimization of Lipari-Szabo Motional Parameters Including Anisotropy of the Diffusion Tensor. The relationship between the amide ${ }^{15} \mathrm{~N}$ relaxation rates and the spectral density function is well-known [adapted from (44)]:

$$
\begin{gathered}
R_{1}=q_{\mathrm{DD}}\left[J\left(\omega_{\mathrm{N}}-\omega_{\mathrm{H}}\right)+3 J\left(\omega_{\mathrm{N}}\right)+6 J\left(\omega_{\mathrm{N}}+\omega_{\mathrm{H}}\right)\right]+ \\
q_{\mathrm{CSA}} J\left(\omega_{\mathrm{N}}\right) \\
R_{2}=\left({ }^{1}{ }_{2}\right) q_{\mathrm{DD}}\left[4 J(0)+J\left(\omega_{\mathrm{N}}-\omega_{\mathrm{H}}\right)+3 J\left(\omega_{\mathrm{N}}\right)+\right. \\
\left.6 J\left(\omega_{\mathrm{H}}\right)+6 J\left(\omega_{\mathrm{N}}+\omega_{\mathrm{H}}\right)\right]+\left(1 /_{6}\right) q_{\mathrm{CSA}}\left[4 J(0)+3 J\left(\omega_{\mathrm{N}}\right)\right] \\
\mathrm{NOE}=1+\left(\gamma_{\mathrm{H}} / \gamma_{\mathrm{N}}\right) q_{\mathrm{DD}}\left[6 J\left(\omega_{\mathrm{N}}+\omega_{\mathrm{H}}\right)-\right. \\
\left.J\left(\omega_{\mathrm{N}}-\omega_{\mathrm{H}}\right)\right]\left(1 / R_{1}\right)
\end{gathered}
$$

where $q_{\mathrm{DD}}=\left({ }^{1} / 10\right)\left(\mu_{0} / 4 \pi\right)^{2} \hbar^{2} \gamma_{\mathrm{N}}{ }^{2} \gamma_{\mathrm{H}^{2}} r_{\mathrm{HN}}{ }^{-6} ; q_{\mathrm{CSA}}=\left({ }^{2} / 15\right) \omega_{\mathrm{N}}{ }^{2}-$ $\Delta \sigma^{2} ; \mu_{0}$ is the permeability in a vacuum; $\hbar$ is Planck's constant divided by $2 \pi ; \omega_{\mathrm{N}}$ and $\omega_{\mathrm{H}}$ are the Larmor frequencies of the ${ }^{15} \mathrm{~N}$ and ${ }^{1} \mathrm{H}$ spins, respectively; $\gamma_{\mathrm{N}}$ and $\gamma_{\mathrm{H}}$ are the gyromagnetic ratios of the ${ }^{15} \mathrm{~N}$ and ${ }^{1} \mathrm{H}$ spins, respectively; $r_{\mathrm{HN}}$ is the internuclear $\mathrm{H}-\mathrm{N}$ distance; $\Delta \sigma$ is the chemical shift anisotropy of the ${ }^{15} \mathrm{~N}$ nucleus; and NOE is the ${ }^{15} \mathrm{~N}$ $\left\{{ }^{1} \mathrm{H}\right\}$ steady-state nuclear Overhauser effect.

Protein motion is often analyzed by the Model Free approach (45), using a linear combination of Lorentzians for the spectral density function. It has been noted, however, that an accurate determination of the Lipari-Szabo order parameters and correlation times can be severely compro- mised by several factors, e.g., noise on the data, monomerdimer equilibrium, rotational diffusion anisotropy and chemical exchange (45-48).

To identify the most suitable model of the spectral density function for each residue, an iterative procedure was employed:

Step 1. The first cycle is the same as the first cycle of the procedure as described by Li and Montelione (47). After an initial guess for the overall rotational correlation time $\left(\tau_{\mathrm{m}}\right)$, the Lipari-Szabo motional parameters for each residue are calculated. This is repeated six times, each time assuming a different spectral density function (see Table 1). The bestfit model for each residue is determined employing the following criteria: $R_{\mathrm{ex}}$ was introduced when its value exceeded the noise on the data. The model with the lowest $\chi^{2}$, was accepted, and in case of equal $\chi^{2}$, the simpler model was preferred. Subsequently, $\tau_{\mathrm{m}}$ is optimized by simultaneous fitting with the other Lipari-Szabo parameters. All residues for which the relaxation rates could be reliably determined were included in this first step. Residues exhibiting largeamplitude fast internal motion (identified by ${ }^{15} \mathrm{~N}\left\{{ }^{1} \mathrm{H}\right\} \mathrm{NOE}$ $<-0.4$ ) and residues exhibiting significant contributions to the line width from chemical exchange $\left(R_{\mathrm{ex}}>2 \mathrm{~Hz}\right)$ were identified.

Step 2. The analysis of the anisotropy of the rotational diffusion tensor was performed with the program quadric1.1 $(49,50)$. For each spin, (i) a local diffusion constant $D_{\mathrm{i}}=$ $\left(6 \tau_{\mathrm{m}, \mathrm{i}}\right)^{-1}$ is defined, based on $R_{2, \mathrm{i}}$ and $R_{1, \mathrm{i}}$. Least-squares fitting procedures to optimize the fit between the $D_{\mathrm{i}}$ values and the input structure were performed, to determine the diffusion tensor for asymmetric, symmetric, and spherical rotators. Since all differences in $R_{2, \mathrm{i}}$ and $R_{1, \mathrm{i}}$ with respect to the $R_{2}$ and $R_{1}$ values averaged over the entire sequence are interpreted in terms of anisotropic diffusion, care must be taken to exclude the previously determined residues with large-amplitude fast time scale dynamics and residues subject to chemical exchange line broadening from the analysis.

The rotational anisotropy in the diffusional model as well as the relative orientation of the diffusion axes in the model could be determined. Since the axially symmetric diffusion tensor provided a significant improvement over the isotropic model, the angle of each $\mathrm{NH}$ vector with respect to the parallel axis of the diffusion tensor $(\theta)$ could be derived.

As input structures, model 20 of the ensemble of RXR solution structures (10) was chosen for the free RXR, because it is closest to the average structure. For the complex, no complete model was available. The RXR molecule plus the central RXR half-site with one flanking base pair on either 


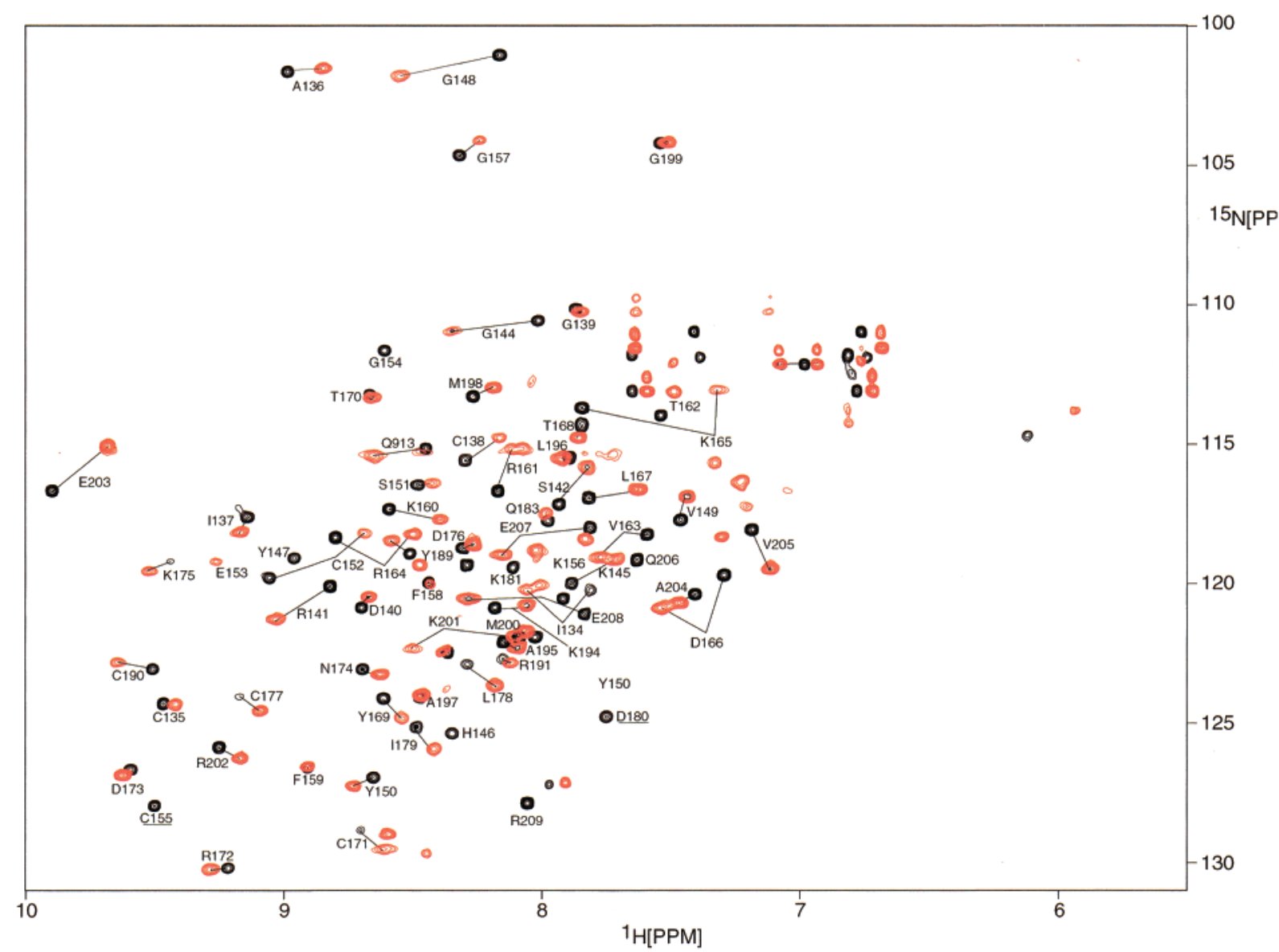

FIGURE 1: Overlay of the $\left\{{ }^{15} \mathrm{~N}-{ }^{1} \mathrm{H}\right\}$ HSQC spectra of RXR free in solution (black) and complexed with DNA (red). The underlined residues represent signals too weak for reliable relaxation analysis (see text for further details).

side, extracted from the crystal structure of the RXR and TR on a DR4 (15), lacks the coordinates for a total of 6 base pairs and 10 residues [representing approximately 4.5 $\mathrm{kD}(15 \%)$ of the total weight of the complex]. A more complete model of the RXR-DNA complex, which was used in the analysis of the rotational diffusion anisotropy, was constructed (see Figure 6): The crystal structure of RXR/TR/DR4 served as a basis. TR was removed, and DR4 was replaced by a stretch of B-DNA of 14 base pairs. Furthermore, the third helix, present in the solution structure of RXR (10) was added to the crystal structure.

Step 3. This step is similar to step 1, but now anisotropy of the rotational diffusion was taken into account. It is implemented by exchanging the (global) $\tau_{\mathrm{m}}$ in the calculations by the anisotropy-corrected value of $\tau_{\mathrm{m}}$ for each residue $\left(\tau_{\mathrm{m}, \mathrm{i}}\right)$, which is calculated from the diffusion constants parallel $\left(D_{\|}\right)$and perpendicular $\left(D_{\perp}\right)$ to the symmetry axis of the diffusion tensor and $\theta$. The determination of the best-fit spectral density function was performed as before. All residues were taken into account in this step. The error in the fitted parameters and their reliability were calculated using a Monte Carlo procedure (using 500 steps) as described by Mandel et al. (52). From this procedure, standard deviations and bias were obtained for each fitted parameter. The bias was defined as $\left(P_{\text {fit }}-\left\langle P_{\mathrm{bc}}\right\rangle\right) / P_{\text {fit }}$, where $P_{\text {fit }}$ and $P_{\mathrm{bc}}$ represent the relaxation parameter based on the initial fit and the Monte Carlo simulation, respectively. Models for which the bias of one of the fitted parameter exceeded 0.1 were discarded and a simpler model was chosen.

\section{RESULTS}

Relaxation Rates and Overall Correlation Time. The overlay of the HSQC spectra of the free and complexed RXR (see Figure 1) reveals that virtually every resonance has shifted upon complex formation. In Figure 2 the $T_{1}$ and $T_{1 \rho}$ decay curves for three residues are shown, both free and complexed with DNA. Relaxation rates for the cadmium substituted RXR, both free in solution and in complex with DNA, are shown in Figure 3. The average transverse and longitudinal relaxation rates are 18.1 and $1.29 \mathrm{~Hz}$ for RXR in the complex and 9.06 and $1.90 \mathrm{~Hz}$ for RXR free in solution. The NOE values [plotted as $\left(I_{\mathrm{sat}}-I_{\mathrm{o}}\right) / I_{\mathrm{o}}$, where $I_{\text {sat }}$ and $I_{\mathrm{o}}$ are the peak intensity with and without heteronuclear NOE, respectively), were -0.30 and -0.25 for RXR in the complex and free in solution, respectively. A number of residues were omitted from the analysis. These include the $\mathrm{N}$-terminal residues 132 and 133. Furthermore, residues 143, 155,180 , and 187 in the complex have been assigned, but the peak intensities for these residues in the relaxation spectra were too weak to allow reliable interpretation. The backbone $\mathrm{N}-\mathrm{H}$ resonances of the remaining residues (free RXR, 143, 153, 184-188; complexed RXR, 147, 154, 156, 181-184, 188 , and 206) were not visible in the spectra, whereas many of the ${ }^{13} \mathrm{C}$ and aliphatic resonances could be assigned. Measurements performed at $3{ }^{\circ} \mathrm{C}$ employing a water flipback strategy to avoid saturation transfer from $\mathrm{H}_{2} \mathrm{O}$ yielded only few additional cross-peaks, belonging to arginine sidechain $\mathrm{N}^{\epsilon}-\mathrm{H}^{\epsilon}$ resonances. As arginine side-chain protons are generally much more labile than backbone amide groups, it 

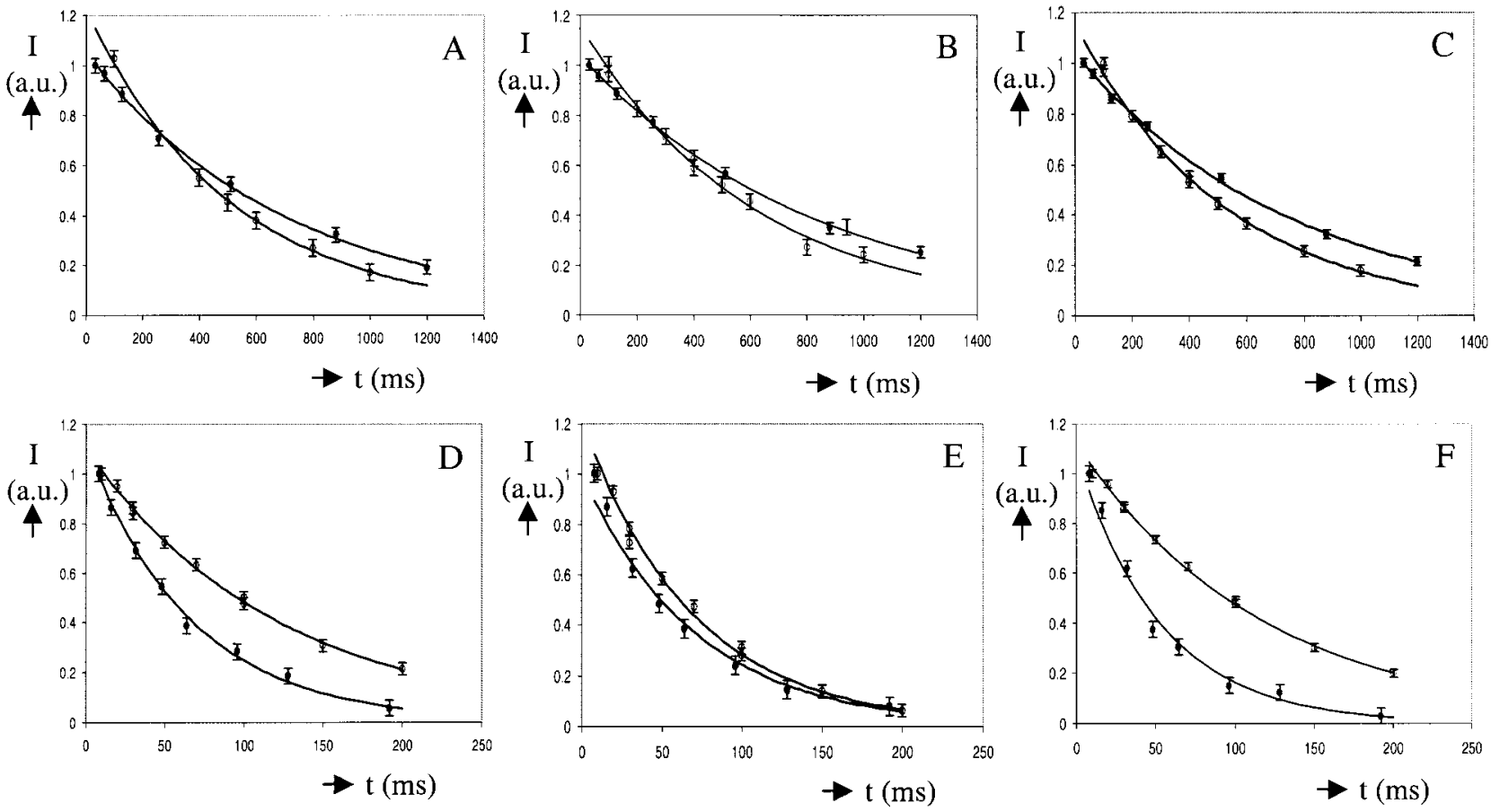

Figure 2: $T_{1}(\mathrm{~A}-\mathrm{C})$ and $T_{1 \rho}(\mathrm{D}-\mathrm{F})$ relaxation decay curves for residues $135(\mathrm{~A}, \mathrm{D}), 178(\mathrm{~B}, \mathrm{E})$, and $194(\mathrm{C}, \mathrm{F})$ of RXR free in solution (-) and complexed with DNA $(O)$. The intensities are scaled relative to the first point of each curve.

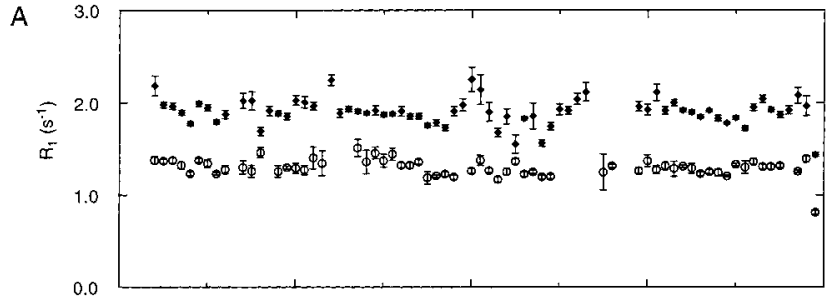

B
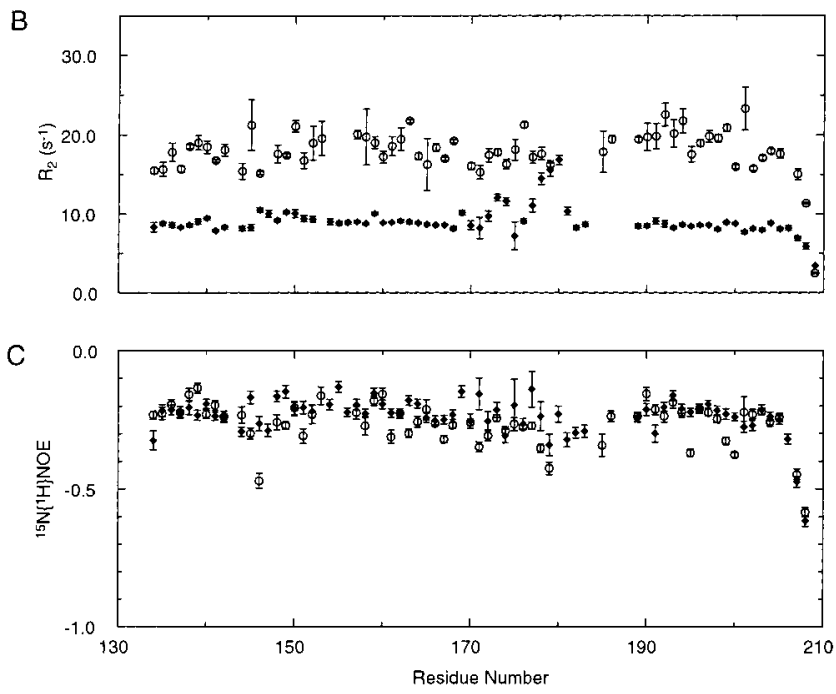

FIGURE 3: (A) $R_{1}$, (B) $\mathrm{R}_{2}$, and (C) ${ }^{15} \mathrm{~N}\left\{{ }^{1} \mathrm{H}\right\}$ NOE values as a function of residue number for RXR free in solution $(\bullet)$ and RXR in complex with DNA $(\mathrm{O})$. The spectra for the free protein are recorded at $600 \mathrm{MHz}$, whereas the spectra for the complex are recorded at $500 \mathrm{MHz}$.

was concluded that the missing resonances were broadened beyond detection by intermediate time-scale dynamics. The relaxation behavior of the Cd-substituted RXR is virtually identical to that of the (wild-type) Zn-form (results not shown).
Initial guesses of the overall rotational correlation time $\left(\tau_{\mathrm{m}}\right)$, assuming isotropic rotation, were based on the $R_{2}$ and $R_{1}$ values of all residues. They were found to be $6.00 \mathrm{~ns}$ for RXR free in solution and $13.85 \mathrm{~ns}$ for RXR complexed to DNA. After simultaneous optimization of $\tau_{\mathrm{m}}$ with the Lipari-Szabo motional parameters, the optimized $\tau_{\mathrm{m}}$ remained virtually unchanged: 5.95 and $13.85 \mathrm{~ns}$ for RXR free in solution and in the complex, respectively.

Both RXR Free in Solution and in the Half-Site Complex Are Best Described by an Axially Symmetric Diffusion Tensor. Residues 207-209 in the free protein and residues 146, 179, and 207-209 in the complex showed large amplitude fast internal motions. In step 1 of the analysis, residues $146-147,149,157,172-174$, and $178-181$ in the free protein and residues 150, 153, 157, 161-163, 169, 176, 192, 194, 198, 199, and 201 in the complex were identified to exhibit exchange contributions to the transverse relaxation times of at least $10 \%$ (cutoffs of $1 \mathrm{~Hz}$ for the free protein and $2 \mathrm{~Hz}$ for the complex were employed). A total of five residues in the complex $(134,202-205)$ were excluded from the analysis because they are lacking from the crystal structure of RXR. The remaining residues (54 for the free protein and 36 for the complex) were used in the rotational diffusion analysis. The ratios of the moments of inertia (1: 0.70:0.58 for the free protein and 1:0.83:0.53 for the complex) already indicate a nonspherical shape for the molecule. Indeed, the axially symmetric description of the diffusion tensor provides a statistically significant improvement over the isotropic model. However, no distinction can be made between the axial oblate and axial prolate form (see Table 2). On the basis of the moments of inertia in conjunction with the inability to distinguish between oblate and prolate, one might expect that the rotational diffusion tensor should be best described by a fully anisotropic model. However, several factors compromise the accuracy and the precision of the diffusion tensor determination: (1) inac- 


\begin{tabular}{|c|c|c|c|c|c|c|c|c|c|}
\hline tensor & $\begin{array}{c}D_{\text {iso }} \\
\left(10^{+7} \mathrm{~s}^{-1}\right)\end{array}$ & $2 D_{z z} /\left(D_{x x}+D_{y y}\right)$ & $D_{x x} / D_{y y}$ & $\begin{array}{c}\theta \\
(\mathrm{rad})\end{array}$ & $\begin{array}{c}\varphi \\
(\mathrm{rad})\end{array}$ & $\begin{array}{c}\psi \\
(\mathrm{rad})\end{array}$ & $\chi^{2}$ & $F^{\mathrm{a}}$ & $\begin{array}{c}P^{b} \\
(\%)\end{array}$ \\
\hline \multicolumn{10}{|l|}{ free RXR } \\
\hline isotropic & $2.76 \pm 0.01$ & & & & & & 145 & & \\
\hline axial (oblate) & $2.78 \pm 0.01$ & $0.84 \pm 0.02$ & & $1.27 \pm 0.09$ & $0.17 \pm 0.10$ & & 87 & 11.1 & 0.001 \\
\hline axial (prolate) & $2.78 \pm 0.01$ & $1.27 \pm 0.02$ & & $1.64 \pm 0.06$ & $4.90 \pm 0.09$ & & 89 & 10.5 & 0.002 \\
\hline anisotropic & $2.78 \pm 0.01$ & $1.15 \pm 0.03$ & $1.12 \pm 0.04$ & $1.51 \pm 0.11$ & $-0.33 \pm 1.47$ & $-0.53 \pm 1.08$ & 80 & 2.16 & 15 \\
\hline \multicolumn{10}{|l|}{ complex } \\
\hline isotropic & $1.21 \pm 0.01$ & & & & & & 162 & & \\
\hline axial (oblate) & $1.20 \pm 0.01$ & $0.82 \pm 0.03$ & & $1.12 \pm 0.07$ & $1.50 \pm 0.21$ & & 110 & 5.00 & 0.6 \\
\hline axial (prolate) & $1.20 \pm 0.01$ & $1.26 \pm 0.04$ & & $0.34 \pm 0.06$ & $4.14 \pm 0.07$ & & 103 & 6.16 & 0.2 \\
\hline anisotropic & $1.20 \pm 0.01$ & $1.24 \pm 0.04$ & $1.15 \pm 0.04$ & $0.41 \pm 0.05$ & $1.21 \pm 0.30$ & $-0.14 \pm 0.28$ & 87 & $3.22 / 2.35^{c}$ & $2.65 / 7.74^{c}$ \\
\hline
\end{tabular}

${ }^{a} F$-test to determine the statistical significance of decrease in $\chi^{2}$ with the increase in fitting parameters. ${ }^{b}$ The probability $(P)$ that the observed improvement of the fit is obtained by chance. ${ }^{c}$ The first and second number represent the statistics of the anisotropic model versus the axial oblate and prolate, respectively.
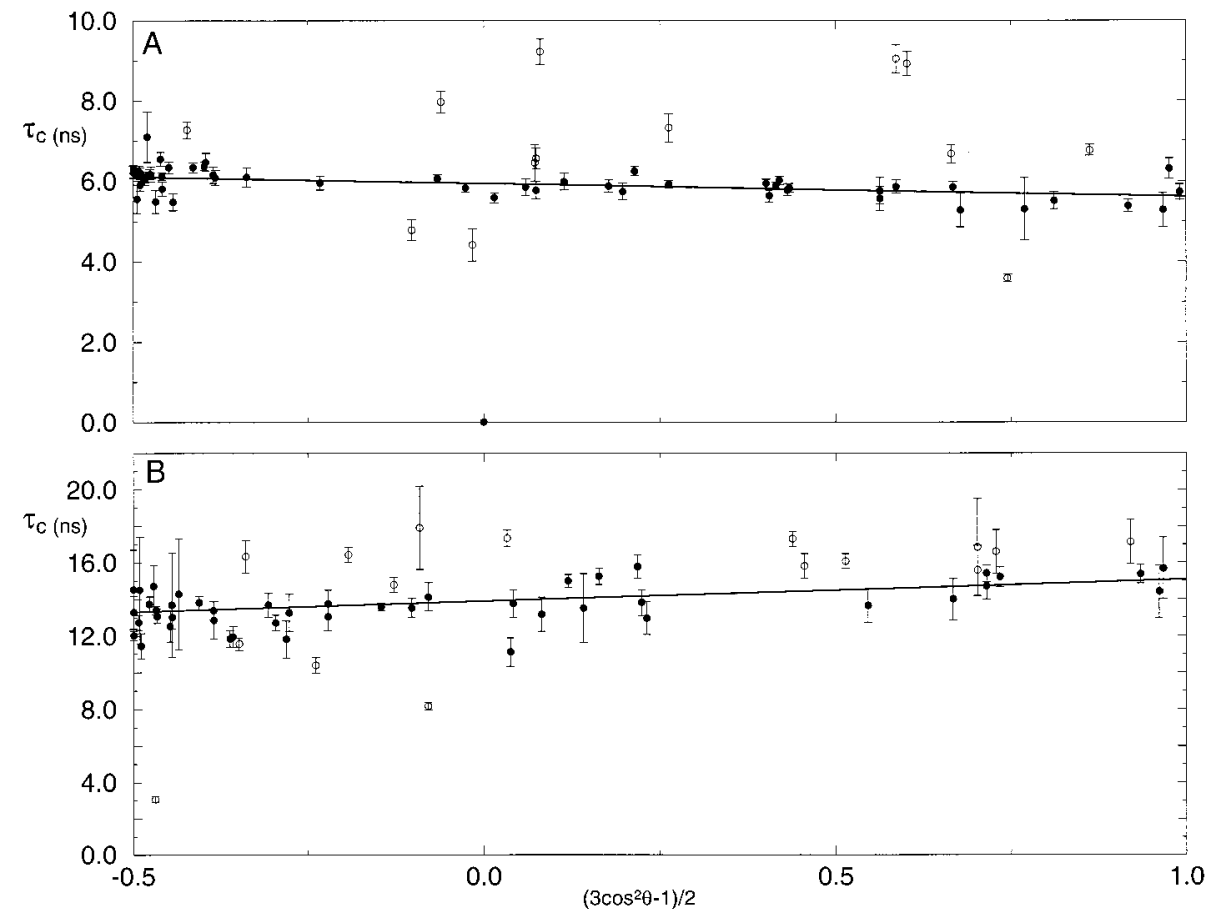

FIGURE 4: Dependence of the local $\tau_{\mathrm{c}}$ on $\left(3 \cos ^{2} \theta-1\right) / 2$, where $\theta$ represents the angle between the $\mathrm{N}-\mathrm{H}$ vector and the unique axis of the symmetric diffusion tensor for the free (A) and complexed (B) RXR DBD. The lines represent the determined correlation given by $D_{\mathrm{i}}$ $=\left\{6 D_{\text {iso }}-2\left[3 \cos ^{2} \theta\left(D_{\text {par }}-D_{\text {per }}\right)\right]\right\}^{-1}$. The open circles represent residues which have been omitted from the anisotropic analysis because they were subject to substantial dynamics (see text for details).

curacy of the $R_{2} / R_{1}$ values, (2) unequal distribution of the HN bond vector orientations (see Figure 4) (51), and (3) the accuracy and completeness of the structural model of the complex used in the determination of the diffusion tensor.

Figure 4 shows that for the complex the accuracy and distribution of the $\left[\left(3 \cos ^{2} \theta-1\right) / 2, \tau_{c, \text { local }}\right]$ pairs to be less good in the complex than in the free protein, which is also reflected by the values for the $P$-statistics. It can be clearly seen in Figure 4 that the residues omitted from the anisotropy analysis have substantially deviating $\tau_{\text {c.local }}$ values when compared with the majority of residues. With respect to the structural models used in this analysis, it can be noted that it was easier to find a good model for the free RXR than for the complex. Employing the extended model of the proteinDNA complex, based on the X-ray structure (see Materials and Methods), rather than the X-ray structure itself, improves the fit between the experimentally determined diffusion tensor with respect to the calculated inertia tensor (results not shown). Systems which might be truly anisotropic are approximated by the simpler axially symmetric tensor. This approximation may yield two minima for $\chi^{2}$ (see Table 2), representing prolate and oblate approximations to the real, more complex form of the molecule $(53,54)$. For the remainder of the analysis, the axial oblate model was assumed for the protein free in solution and the axial prolate model for RXR in complex with DNA.

Interpretation of the ${ }^{15} N$ Relaxation Data of RXR Free in Solution and Complexed with DNA in Terms of the Model Free Approach. There is little pico- to nanosecond timescale internal motion in RXR, either free in solution or complexed with DNA (see Figure 5). Overall, the most rigid parts $\left(S^{2}>0.9\right)$ are the three helices and a number of residues in the first zinc finger. The only residues with substantial large amplitude fast internal dynamics $\left(S^{2}<0.6\right)$ are in the termini (residues 134 and 207-209). In the uncomplexed RXR little internal dynamics $\left(0.6<S^{2}<0.9\right)$ is located in the first zinc finger, the extended region, which connects the first helix with the second zinc finger (165-168), and 

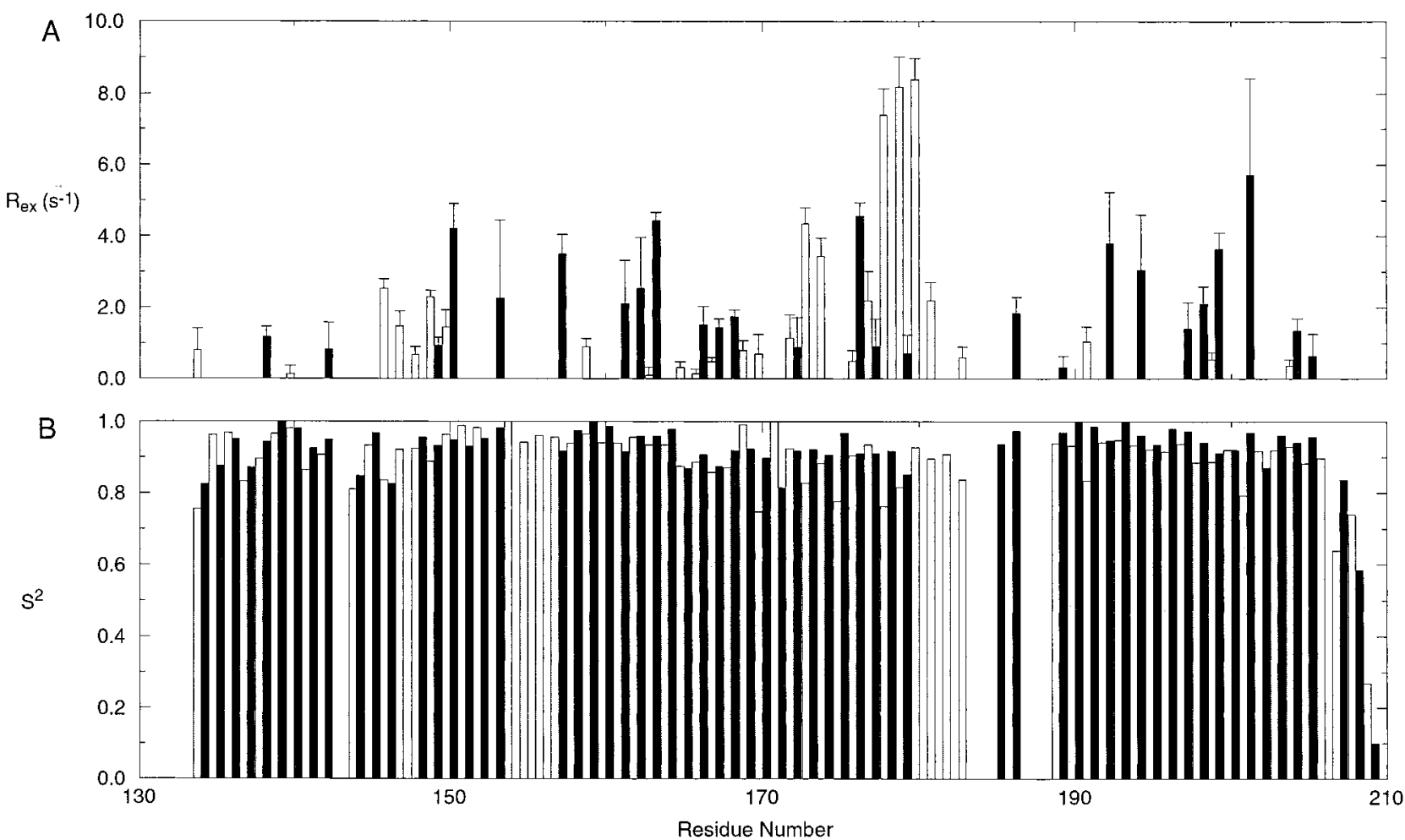

FIGURE 5: Contribution of exchange to the ${ }^{15} \mathrm{~N}$ transverse relaxation rates (A) and the Lipari-Szabo order parameter $\left(S^{2}\right)(\mathrm{B})$, as a function of residue number. The light gray and the black bars indicate RXR free in solution and in the complex, respectively. The values have been derived from Lipari-Szabo analysis with an axial model for the overall tumbling.

the second zinc finger. Overall, the $S^{2}$ values experience a slight increase upon complex formation. Especially for RXR free in solution, incorporation of an anisotropic diffusional model decreases the number of residues with complicated forms of the spectral density (models $3-6$ ) as best-fit. $S^{2}$, $S_{\mathrm{s}}^{2}, S_{\mathrm{f}}^{2}, \tau_{\mathrm{c}}$, and $R_{\mathrm{ex}}$ values with standard deviations together with their corresponding motional model and $\chi^{2}$ residual are available as Supporting Information.

Schurr et al. (45) noted that rotational diffusion anisotropy can be mistaken for exchange. A complication inherent to the method is presented by the fact that in order to determine conformational flexibility one needs to know its exact structure. However, in Figure 4 the residues designated highly dynamic $(O)$ fall, in the majority of cases, outside the extrema presented by the tumbling anisotropy (free RXR $5.68<\tau_{\text {c,local }}$ $<6.17$; complexed RXR $\left.13.31<\tau_{\text {c,local }}<15.04\right)$. Therefore, it seems valid to assume that these residues are dynamic and the lack of structure merely results in a larger error on the parameters describing the motion.

In the free protein, the remaining residues subject to chemical exchange are mainly located in two regions (see Figure 5). The tip of the first zinc finger (146-150) and the second zinc finger $(173-175,178-182)$. The data for the complex show the chemical exchange to be randomly distributed throughout the sequence, particularly affecting residues $150,153,157,161-163,169,176,192,194,198$, 199 , and 201. However, the uncertainty on the contributions of chemical exchange to the transverse relaxation rates are rather large as judged by Monte Carlo back-calculations.

Conformational Exchange in RXR. The exchange of ${ }^{15} \mathrm{~N}$ spins, as well as of the amide protons, is probed by comparing the peak intensities in the higher and lower repetition rate CPMG experiments (see Figure 6). The
$I_{\mathrm{CPMG}}^{\mathrm{H}} / I_{\text {ref }}^{\mathrm{H}}$ values for the free protein show elevated values for residues 150, 175, 177-178, which coincide with the regions in which chemical exchange was identified for the nitrogen spins. When RXR is in complex with DNA, the $I_{\mathrm{CPMG}}^{\mathrm{H}} / I_{\mathrm{ref}}^{\mathrm{H}}$ values show an elevation over the entire sequence. For the complex, also peak intensity ratios $\left(I_{\text {fast }}^{\mathrm{N}} /\right.$ $I_{\text {slow }}^{\mathrm{N}}$ ) for ${ }^{15} \mathrm{~N}$ were determined, in which exchange can be identified especially for residues 157 and 185 .

\section{DISCUSSION}

Localized Exchange in the Free Protein Is Caused by Conformational Changes. The exchange in the free RXR is highly localized to the second zinc finger and the tip of the first zinc finger. In principle, this exchange broadening could be caused by conformational transitions or by an equilibrium between free and dimerized RXR. GST pull-down experiments (results not shown) were performed in which RXR homodimers could not be detected under near-NMR conditions, in contrast to RXR/RAR heterodimers. This leaves conformational dynamics to be the sole cause for the observed chemical exchange in the free RXR.

Equilibrium between Specific and Aspecific RXR-DNA Complexes. In the complex, even more processes can occur which give rise to chemical exchange, e.g., the equilibria between free and DNA-bound RXR, and between specific and aspecific DNA binding of RXR. Figure 7 shows the correlation between the $I_{\mathrm{CPMG}}^{\mathrm{H}} / I_{\text {ref }}^{\mathrm{H}}$ and $I_{\text {fast }}^{\mathrm{N}} / I_{\text {slow }}^{\mathrm{N}}$ values of the complex and the $\Delta \delta^{2}$, where $\Delta \delta$ represents the amide proton or ${ }^{15} \mathrm{~N}$ chemical shift difference between the free and the DNA-bound RXR in panels A and B, respectively. Several explanations can be given for the deviations between the observed intensity ratio $\left(A_{\mathrm{obs}}\right)$ and the calculated intensity 

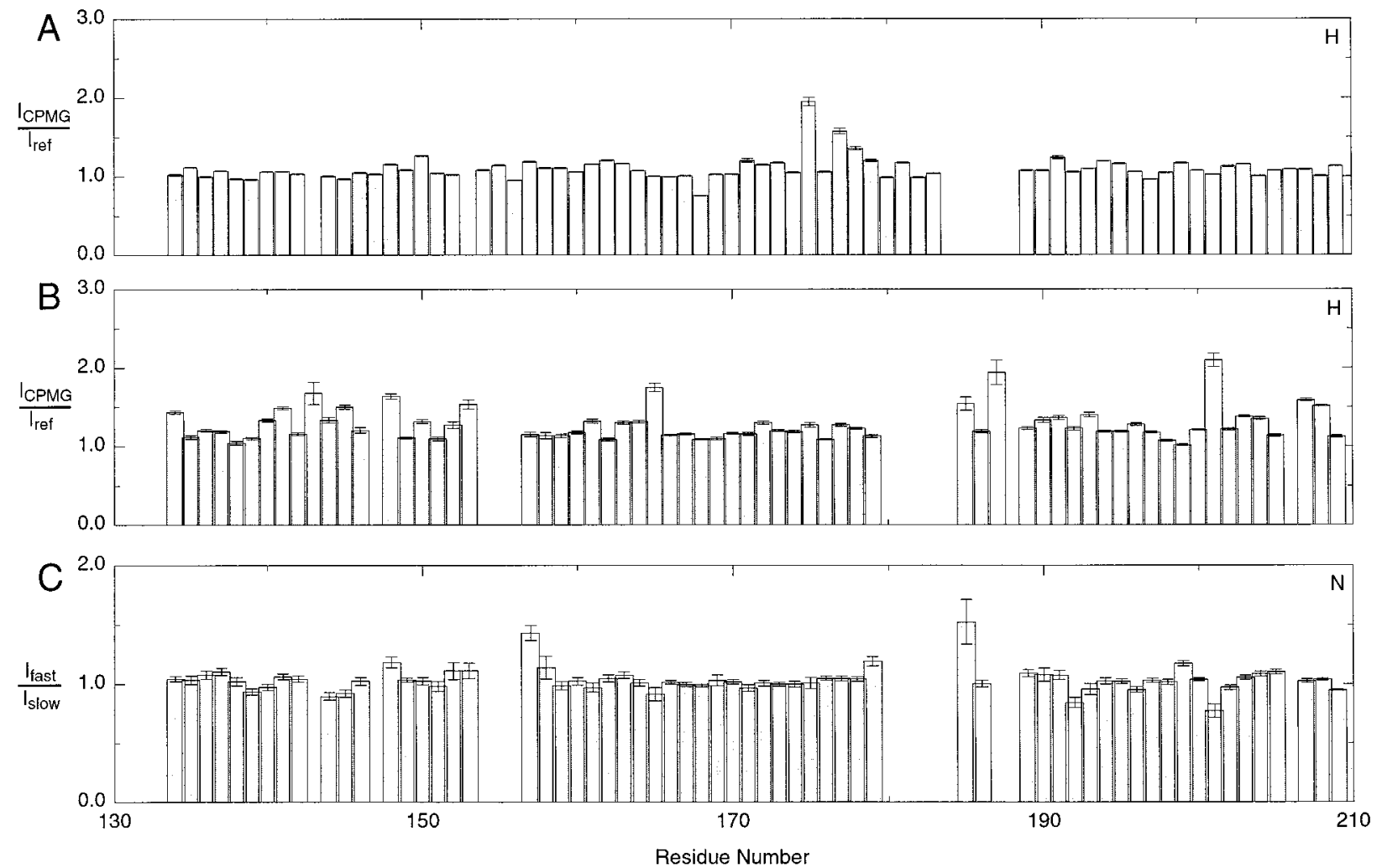

FIGURE 6: Qualitative estimate of the exchange mediated ${ }^{1} \mathrm{H}$ and ${ }^{15} \mathrm{~N}$ relaxation. ${ }^{1} \mathrm{H}$ transverse relaxation data $\left(I_{\mathrm{CPMG}}^{\mathrm{H}} / I_{\text {ref }}^{\mathrm{H}}\right)$ as a function of residue number, for RXR free in solution (A) and in complex with DNA (B). ${ }^{15} \mathrm{~N}$ transverse relaxation data $\left(I_{\text {fast }}^{\mathrm{N}} / I_{\text {slow }}^{\mathrm{N}}\right)$ as a function of residue number for RXR in complex with DNA (C).
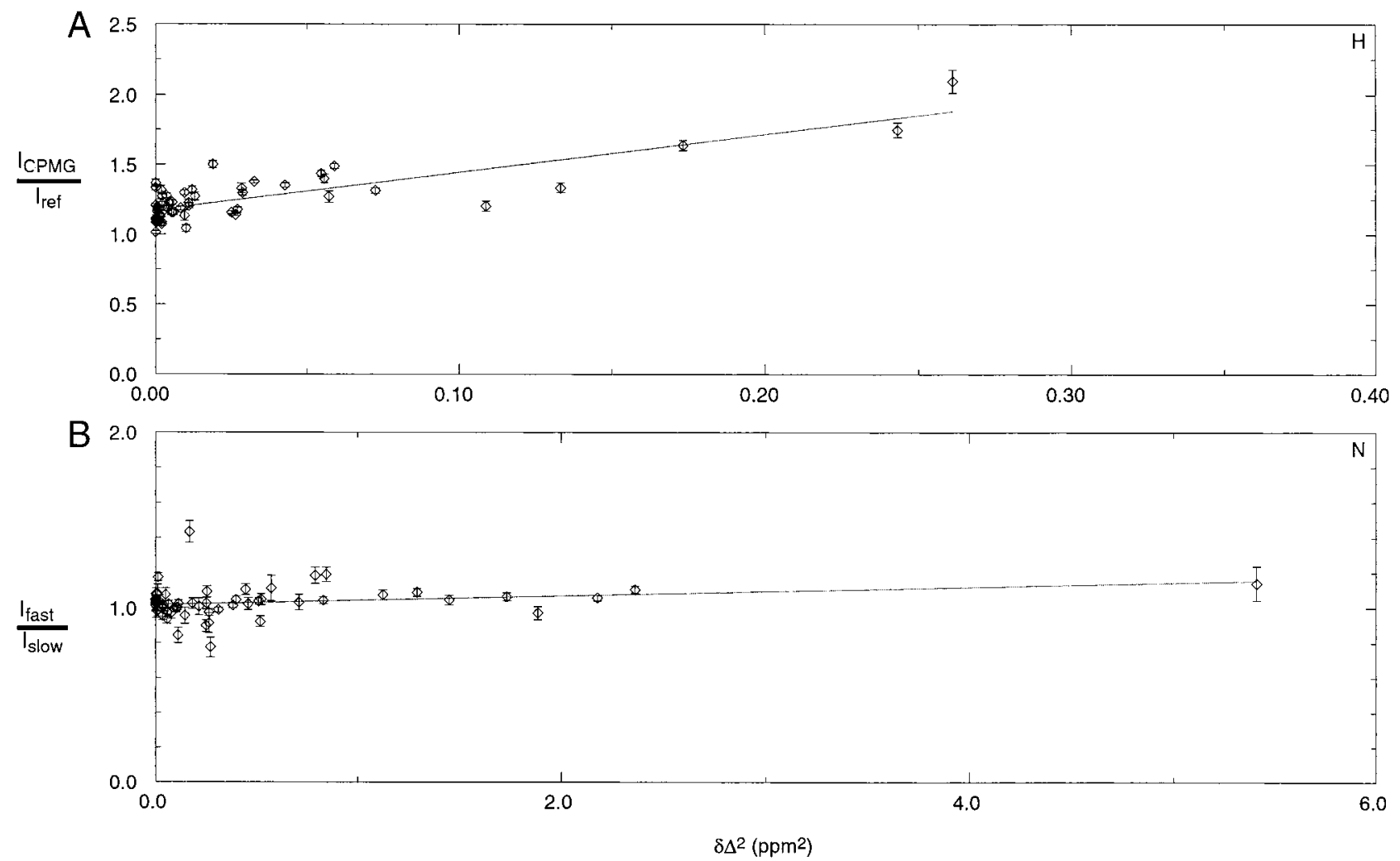

Figure 7: ${ }^{1} \mathrm{H}\left(I_{\mathrm{CPMG}}^{\mathrm{H}} / I_{\text {ref }}^{\mathrm{H}}\right)(\mathrm{A})$ and ${ }^{15} \mathrm{~N}\left(I_{\mathrm{fas}}^{\mathrm{N}} / I_{\text {slow }}^{\mathrm{N}}\right)(\mathrm{B})$ transverse relaxation data as a function of $\Delta \delta^{2}$, where $\Delta \delta$ is the chemical shift difference between the RXR free in solution and in complex with DNA.

ratios from linear regression line-fitting to the data points ( $A_{\text {calc }}$ ), as well as deviation of $A_{\text {obs }}$ from 1 for $\Delta \delta=0$. When assuming a free/bound equilibrium, additional exchange processes (e.g., conformational exchange at the proteinDNA interface) may play a role. Second, imperfect balancing of the CPMG-HSQC and the reference HSQC, or other 


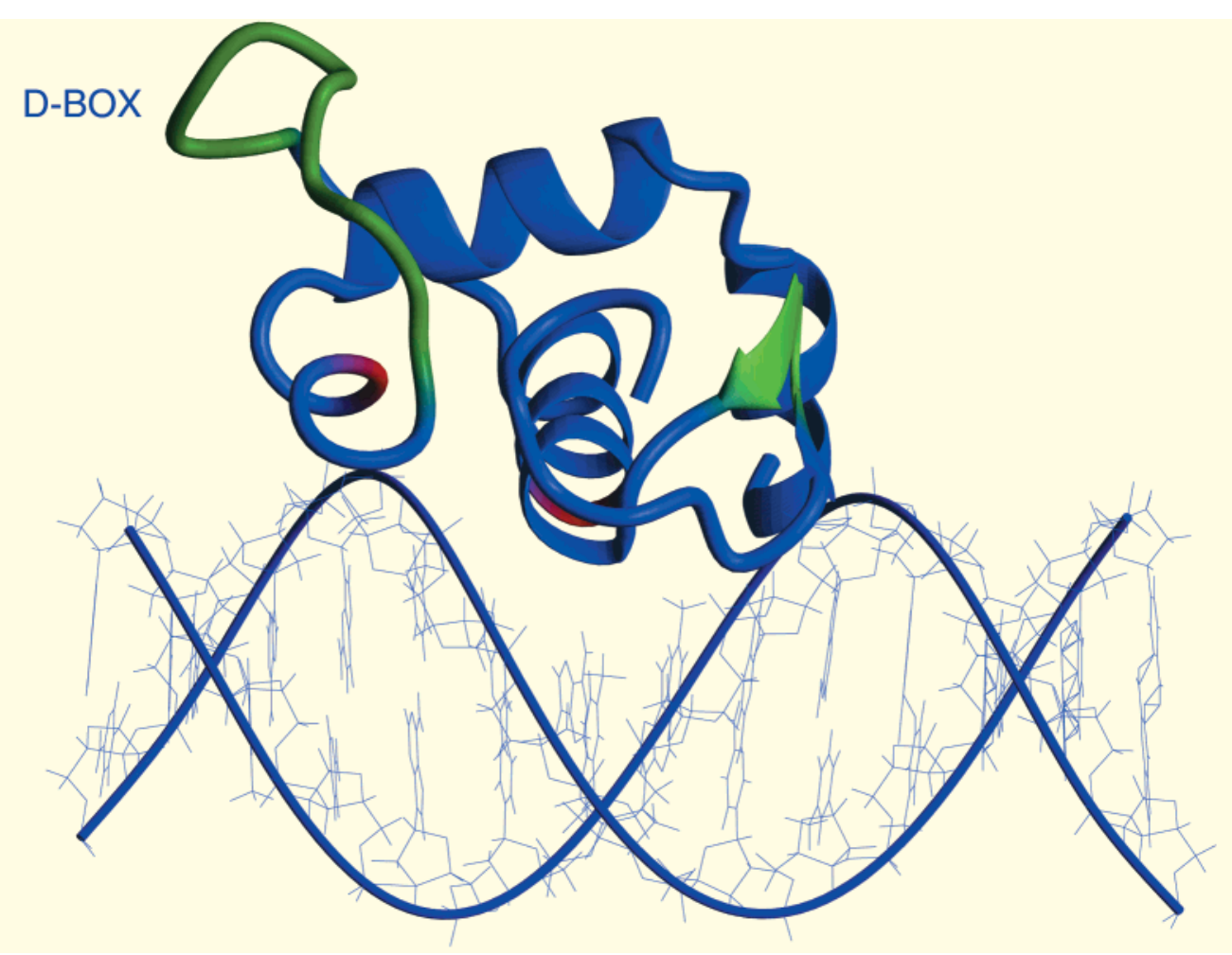

FIGURE 8: Model of the RXR-DNA structure used for the analysis of the rotational diffusion anisotropy (based on the RXR/TR/DR4 as described in the Materials and Methods). Note that the third helix as found in the solution structure of the free RXR is included in this model. The backbone of RXR is color coded according to the differences in exchange mediated transverse relaxation between RXR free in solution and in the complex. The residues which exhibit exchange solely in the free protein, are depicted in green. Shown in red are residues 157 and 185, which exhibit exchange in the complex that cannot be accounted for by the specific/aspecific equilibrium. The picture was generated using MOLMOL (57).

artifacts, may give rise to these deviations. If an equilibrium between specific and aspecific DNA-bound RXR is dominant, the correlation shown in Figure 5 implies that the chemical shifts of RXR in the aspecific complex resemble those of RXR free in solution. Deviations between $A_{\mathrm{obs}}$ and $A_{\text {calc }}$ could then result from differences in chemical shifts between the unbound RXR and aspecifically bound RXR. The rather substantial difference between the slopes for the amide protons and the ${ }^{15} \mathrm{~N}$ nuclei in Figure 7 is explained by a combination of two factors. First of all, the signal intensities in the four experiments (two for proton and two for nitrogen) are all differently affected by exchange. In case of the proton experiments, the difference in exchangemediated transverse relaxation is much larger than for the two nitrogen experiments. Furthermore, the chemical shift differences (in hertz) for nitrogen are, in general, smaller than the chemical shift differences for proton. Since the kinetics are in the medium to fast exchange regime for the signals (see below), the observable effect on nitrogen will be smaller than for proton.

Discrepancies between the contribution of chemical exchange to the transverse relaxation rates, derived from either the Lipari-Szabo analysis or the CPMG- $T_{2}$ measurements, are explained by the large errors on the former. The Monte Carlo back-calculations indicate possible variations in $R_{\mathrm{ex}}$ up to $50 \%$, which is ample to obscure the subtle relationship between between $R_{\mathrm{ex}}$ and the differences between the chemical shifts of RXR in the free and the bound state.

Both a monomer-dimer equilibrium on DNA as a free/ bound equilibrium can influence the analysis of the relaxation data of the complex $(46,55)$. Zechel et al. $(56,57)$ reported that, in contrast to RXR-RAR heterodimerization, no homodimerization occurs on a DNA half-site. To distinguish between the free/bound and specific/aspecific equilibrium, the sample of the complex was diluted by a factor of 10 . None of the resulting chemical shift changes in the spectrum exceeded $0.01 \mathrm{ppm}$, suggesting that virtually all the protein is present in the DNA-bound form, which discards the free/ bound equilibrium. Another line of evidence supporting a specific/aspecific equilibrium rather than a free/bound equilibrium is provided by the off-rate of the complex. Since the increasing slope of $A_{\mathrm{obs}}$ with increasing $\Delta \delta^{2}$ indicates a medium-fast exchange regime, the exchange process should occur in the millisecond (or faster) time range. The binding strength restricts the off-rate to values significantly slower than this. Furthermore, the off-rates in the RXR-DNA complex derived with biochemical methods were found to be in the order of minutes (data not shown). A number of residues remained unassigned, which is either due to saturation transfer of the amide signal due to exchange with the water, or exchange line broadening on either of the main nuclei involved in the assignment $\left({ }^{1} \mathrm{H}^{\mathrm{N}},{ }^{15} \mathrm{~N},{ }^{13} \mathrm{C}^{\alpha}\right)$. If these signals are broadened beyond detection due to exchange, the nature of it is unknown and can involve all of the previously mentioned mechanisms.

Differential Dynamics between Free and Bound RXR Indicate Conformational Constraining of RXR upon DNA Binding. Upon DNA binding, the dynamics of RXR changes completely (see Figure 8). In the complex, chemical exchange resulting from the specific/aspecific equilibrium 
affects many residues throughout the sequence. Moreover, residues 157 and 185 exhibit larger $R_{\mathrm{ex}}$ values than can be expected, based on the chemical shift difference. The presence of both residues at the protein-DNA interface indicates that, here, additional conformational exchange takes place. The most marked difference in dynamics between the free and the bound RXR is observed in the zinc finger regions, the second of which has been identified as one of the major dimerization interfaces in dimeric protein binding to DNA. Major exchange contributions are present in the free protein, which virtually vanish upon formation of the complex. The only indication of residual dynamics is found for residues 170 and 177, which appear to be in slow exchange for the protons. For the stretch 180-184, conformational exchange cannot be excluded. While this work was in progress, the formation of a distorted helix in the second helix was reported for RXR upon binding to a DNA half site (20), whereas at the same time the $\mathrm{C}$-terminal $\alpha$-helix unfolds. Since the dynamical behavior of the $\mathrm{C}$-terminus does not exhibit great changes, it is likely that the helix is replaced by another stable structure.

Previously, differences have been observed between the solution structures of the free DBDs of GR, ER, and RXR on one hand and the crystal structures of these proteins, as homodimers complexed with DNA, on the other. These differences were postulated to result from a folding transition in the DBDs, which occurs upon contacting the DNA (11, 12). We have shown that DNA binding of RXR in solution does result in conformational constraining in the second zinc finger. These findings are complementary to the structural changes in the dimerization areas of RXR induced by DNA binding $(20,10)$. The dynamical behavior of the nuclear receptor DBDs (especially in the milli- to microsecond time scale) displays quite a variety. It is quite likely that this differential dynamics is an important element in intermolecular recognition during complex formation.

\section{ACKNOWLEDGMENT}

We would like to thank Erika C. van Heerde and Dr P. T. van der Saag and Dr. Y. Karimi-Nejad for providing the clone of the RXR DBD and assistance in protein production and purification.

\section{SUPPORTING INFORMATION AVAILABLE}

Table containing $S^{2}, S_{\mathrm{s}}^{2}, S_{\mathrm{f}}^{2}, \tau_{\mathrm{c}}$, and $R_{\mathrm{ex}}$ values with standard deviations together with their corresponding motional model and $\chi^{2}$ residual. This material is available free of charge via the Internet at http://pubs.acs.org.

\section{REFERENCES}

1. Mangelsdorf, D. J., Umesono, K., and Evans, R. M. (1994) The retinoid receptors. In The retinoids: biology, chemistry and medicine, 2nd edition (Sporn, M. B., Roberts, A. B., and Goodman, D. S., Eds.) Raven Press, New York.

2. Mangelsdorf, D. J., Thummel, C., Beato, M., Herrlich, P., Schütz, G., Umesono, K., Blumberg, B., Kastner, P., Mark, M., Chambon, P., and Evans, R. M. (1995) Cell 83, 835839 .

3. Mangelsdorf, D. J., and Evans, R. M. (1995) Cell 83, 841850 .
4. Härd, T., Kellenbach, E., Boelens, R., Maler, B. A., Dahlman, K., Freedman, L. P., Carlstedt-Duke, J., Yamamoto, K. R., Gustafsson, J.-A., and Kaptein, R. (1990) Science 249, 157160.

5. Schwabe, J. W. R., Neuhaus, D., and Rhodes, D. (1990) Nature 348, 458-461.

6. Lee, M. S., Kliewer, S. A., Provencal, J., Wright, P. E., and Evans, R. M. (1993) Science 260, 1117-1121.

7. Baumann, H., Paulsen, K., Kovács, H., Berglund, H., Wright, A. P. H., Gustafsson, J.-A., and Härd, T. (1993) Biochemistry $32,13463-13471$.

8. Van Tilborg, M. A. A., Bonvin, A. M. J. J., Hård, K., Davis, A. L., Maler, B., Boelens, R., Yamamoto, K. R., and Kaptein, R. (1995) J. Mol. Biol. 247, 689-700.

9. Knegtel, R. M. A., Katahira, M., Schilthuis, J. G., Bonvin, A. M. J. J., Boelens, R., Eib, D., Van der Saag, P. T., and Kaptein, R. (1993) J. Biomol. NMR 3, 1-17.

10. Holmbeck, S. M. A., Foster, M. P., Casimiro, D. R., Sem, D. S., Dyson, H. J., and Wright, P. E. (1998) J. Mol. Biol. 281, 271-284.

11. Schwabe, J. W. R., Chapman, L., Finch, J. T., Rhodes, D., and Neuhaus, D. (1993) Structure 1, 187-204.

12. Luisi, B. F., Xu, W. X., Otwinowski, Z., Freedman, L. P., Yamamoto, K. R., and Sigler, P. B. (1991) Nature 352, 497505.

13. Schwabe, J. W. R., Chapman, L., Finch, J. T., and Rhodes, D. (1993) Cell 75, 567-578.

14. Schwabe, J. W. R., Chapman, L., and Rhodes, D. (1995) Structure 3, 201-213.

15. Rastinejad, F., Perlmann, T., Evans, R. M., and Sigler, P. B. (1995) Nature 375, 203-211.

16. Zhao, Q., Khorasanizadeh, S., Miyoshi, Y., Lazar, M. A., and Rastinejad, F. (1998) Mol. Cell 1, 849-861.

17. Van Tilborg, M. A. A. (1998) Ph.D. Thesis, Utrecht University, Utrecht, The Netherlands.

18. Berglund, H., Kovács, H., Dahlman-Wright, K., Gustafsson, J.-A., and Härd, T. (1992) Biochemistry 31, 12000-12011.

19. Berglund, H., Wolf-Watz, M., Lundbäck, T., Van den Berg, S., and Härd, T. (1997) Biochemistry 36, 11188-11197.

20. Holmbeck, S. M. A., Dyson, H. J., and Wright, P. E. (1998) J. Mol. Biol. 284, 533-539.

21. Van Tilborg, P. J. A., Mulder, F. A. A., De Backer, M. M. E., Nair, M., Van Heerde, E. C., Folkers, G., Van der Saag, P. T., Karimi-Nejad, Y., Boelens, R., and Kaptein, R. (1999) Biochemistry 38, 1951-1956.

22. Mulder, F. A. A., Van Tilborg, P. J. A., Kaptein, R., and Boelens, R. (1999) J. Biomol. NMR 13, 275-288.

23. Wikström, A., Berglund, H., Hambraeus, C., Van den Berg, S., and Härd, T. (1999) J. Mol. Biol. 289, 963-979.

24. Spolar, R. S., and Record, M. T. (1994) Science 263, 777784.

25. Zilliacus, J., Wright, A. P. H., Carlstedt-Duke, J., and Gustafsson, J.-A. (1995) Mol. Endocrinol. 9, 389-400.

26. Holmbeck, S. M. A., Dyson, H. J., and Wright, P. E. (1998) J. Mol. Biol. 284, 533-539.

27. Bodenhausen, G., and Ruben, D. J. (1980) Chem. Phys. Lett. 69, 185-189.

28. Grzesiek, S., and Bax, A. (1992) J. Magn. Reson. 96, 432440.

29. Grzesiek, S., and Bax, A. (1992) J. Am. Chem. Soc. 114, 6291-6293.

30. Muhandiram, D. R., and Kay, L. E. (1994) J. Magn. Reson., Ser. B 103, 203-216.

31. Grzesiek, S., and Bax, A. (1993) J. Biomol. NMR 3, 185204.

32. Wittekind, M., and Müller, L. (1993) J. Magn. Reson., Ser. B 101, 201-205.

33. Clubb, R. T., Thanabal, V., and Wagner, G. (1992) J. Biomol. NMR 2, 203-210.

34. Grzesiek, S., Anglister, J., and Bax, A. (1993) J. Magn. Reson., Ser. B 101, 114-119.

35. Davis, A. L., Keeler, J., Laue, E. D., and Moskau, D. (1992) J. Magn. Reson. 98, 207-216. 
36. Kay, L. E., Keifer, P., and Saarinen, T. (1992) J. Am. Chem. Soc. 114, 10663-10665.

37. Cavanagh, J., Palmer, A. G., III, Wright, P. E., and Rance, M. (1991) J. Magn. Reson. 91, 429-436.

38. Delaglio, F., Grzesiek, S., Vuister, G. W., Zhu, G., Pfeifer, J., and Bax, A. (1995) J. Biomol. NMR 6, 277-293.

39. Kleywegt, G. J., Vuister, G. W., Padilla, A., Knegtel, R. M. A., Boelens, R., and Kaptein, R. (1993) J. Magn. Reson., Ser. B 102, 166-176.

40. Vis, H., Vorgias, C. E., Wilson, K. S., Kaptein, R., and Boelens, R. (1998) J. Biomol. NMR 11, 265-277.

41. Düx, P., Rubinstenn, G., Vuister, G. W., Boelens, R., Mulder, F. A. A., Hård, K., Hoff, W. D., Kroon, A. R., Crielaard, W., Hellingwerf, K. J., and Kaptein, R. (1998) Biochemistry 37, 12689-12699.

42. Mulder, F. A. A., Spronk, C. A. E. M., Slijper, M., Kaptein, R., and Boelens, R. (1996) J. Biomol. NMR 8, 223-228.

43. Farrow, N. A., Muhandiram, R., Singer, A. U., Pascal, S. M., Kay, C. M., Gish, G., Shoelson, S. E., Pawson, T., FormanKay, J. D., and Kay, L. E. (1994) Biochemistry 33, 59846003.

44. Abragam, A. (1961) Principles of nuclear magnetism, Clarendon Press, Oxford, U.K.

45. Lipari, G., and Szabo, A. (1982) J. Am. Chem. Soc. 104, 45464570.

46. Schurr, J. M., Hazen, P. B., and Fujimoto, B. S. (1994) J. Magn. Reson., Ser. B 105, 211-224.
47. Tjandra, N., Feller, S. E., Pastor, R. W., and Bax, A. (1995) J. Am. Chem. Soc. 117, 12562-12566.

48. Li, Y. C., and Montelione, G. T. (1995) Biochemistry 34, $2408-2423$.

49. Tjandra, N., Wingfield, P. T., Stahl, S. J., and Bax, A. (1996) J. Biomol. NMR 8, 273-284.

50. Brüschweiler, R., Liao, X., and Wright, P. E. (1995) Science 268, 886-889.

51. Lee, L. K., Rance, M., Chazin, W. J., and Palmer, A. G., III (1997) J. Biomol. NMR 9, 287-298.

52. Mandel, A. M., Akke, M., and Palmer, A. G., III (1995) $J$. Mol. Biol. 246, 144-63.

53. Blackledge, M., Cordier, F., Dosset, P., and Marion, D. (1998) J. Am. Chem. Soc. 120, 4538-4539.

54. Cordier, F., Caffrey, M., Brutscher, B., Cusanovich, M. A., Marion, D., and Blackledge, M. (1998) J. Mol. Biol. 281, 341361.

55. Fushman, D., Cahill, S., and Cowburn, D. (1997) J. Mol. Biol. 266, 173-194.

56. Zechel, C., Shen, X. Q., Chambon, P., and Gronemeyer, H. (1994) EMBO J. 13, 1414-1424.

57. Zechel, C., Shen, X. Q., Chen, J. Y., Chen, Z. P., Chambon, P., and Gronemeyer, H. (1994) EMBO J. 13, 1425-1433.

58. Koradi, R., Billeter, M., and Wüthrich K. (1996) J. Mol. Graph. $14,51-55$.

BI991550G 